\title{
Advances in the Diagnosis of Visceral Leishmaniasis
}

\section{Vijay Kumar Prajapati ${ }^{1 *}$ and Sanjana Mehrotra ${ }^{2}$}

${ }^{1}$ Department of Biochemistry, Central University of Rajasthan, Bandar Sindri, Ajmer, 305 801, Rajasthan, India

${ }^{2}$ Department of Human Genetics, Guru Nanak Dev University, Amritsar-143 005, Punjab, India

Visceral Leishmaniasis (VL or Kala azar) is a disease of poor and neglected populations; it affects 79 countries of the world and accounts 58,000 new cases to each year [1]. Indian subcontinent covers $90 \% \mathrm{VL}$ cases of the world, among which Bihar state accounts for most cases [2]. In absence of antileishmanial vaccines early and accurate diagnosis holds the key for the control of VL. Till date parasitological method remains the gold standard for diagnosing VL. Microscopic demonstration of amastigotes in splenic aspirates, peripheral blood mononuclear cells and buffy coat has been shown to possess high sensitivities and absolute specificity $[3,4]$. Serology based diagnostic methods to detect antibodies against different recombinant Leishmania antigens (rK39, $\mathrm{rK} 28, \mathrm{rK} 16)$ are also routinely employed to detect active cases in the field conditions. Out of these rK39 immunochromatographic test (ICT) remains the test of choice for clinicians because of its $100 \%$ sensitivity in VL subjects and $85-100 \%$ specificity in endemic healthy controls [5]. Recently recombinant antigen $\mathrm{rK16}$, 39-amino acid protein obtained from $\mathrm{C}$ terminus of $L$. donovani immobilized in two different formats, a flow through test (KEFT) or Signal KA, and a lateral flow test (KELF) or Crystal KA had shown higher (sensitivity 93-99\% and $99.5 \%$ respectively) in Indian subcontinent than East Africa and Brazilian VL subjects [6,7].

rK28 was designed to increase antigen epitope density from $L$. donovani haspb1 and rK39 kinesin gene. In ELISA, it has shown 100\% sensitivity in VL subjects and $94 \%$ specificity in endemic healthy controls [6]. Antibody based detection methods have two major limitations. Although antibody titre level goes down after successful VL treatment, it still can be detected after many years. Secondly, house hold contacts from VL patient families have shown positivity for antileishmanial antibodies. Sero-prevalence in these individuals varies from $10-30 \%$ and they are termed as asymptomatic cases. Therefore, antibody based approaches should be confirmed with other VL defining tools before treatment [8]. In order to develop non invasive diagnosis for $\mathrm{VL}$, the strip tests have been evaluated using human saliva which is a good source of anti-leishmanial antibodies. Sensitivity for $r$ K39 antigen using saliva was $83.3 \%$ and $82.5 \%$ in ELISA and ICT technique, whereas specificity was found to be $90.5 \%$ and $91.5 \%$ respectively by ELISA and ICT in endemic healthy controls [9]. A recent study from Bangladesh has shown satisfactory results with urine samples of VL patients and endemic controls with rK39 based ICT (93.3\% specificity and 95\% sensitivity) [10]. Since the reliability of these RDTs in any region depends upon the manufacturer, therefore quality and performance should be checked before implementing these RDTs for VL diagnostic algorithm. In immune-compromised patients (HIV-VL co-infection) antibody titre is low therefore RDTs should be evaluated properly in clinical settings to define VL subjects and treatment recommendations.

Antigen based diagnosis is more specific than antibody based methods because it can also be performed in the immune-compromised patients with low antibody titre. Two polypeptide fractions 72-74 $\mathrm{kDa}$ and $123 \mathrm{kDa}$ were reported in the VL subject's urine samples, first polypeptide had shown $96 \%$ sensitivity and $100 \%$ specificity and surprisingly these antigens were not detectable after successful treatment of VL subjects, which predicts very good prognostic value [11] .
Molecular based methods for VL diagnosis have been developed and evaluated to overcome the limitations of parasitological (high invasiveness and non applicability to field conditions) and serological methods (low prognostic value). These methods are primarily based on qualitative PCR and involve amplifying parasite DNA in VL patient's blood sample. Various regions of leishmania genome have been targeted (high copy number kDNA, small subunit of rRNA, ITS1) to develop highly specific and sensitive primers [12]. Noninvasive samples like buccal swabs have also been evaluated using PCR and have been shown to give encouraging results [13]. More recently, quantitative PCR with its high sensitivity, shorter run times and reduced contamination risks has been introduced and currently being evaluated in clinical settings $[14,15]$. Another technology, Nucleic acid sequence-based amplification (NASBA) can be a better marker of active disease and cure as it involves amplification of specific RNA sequences [16]. The major thrust in molecular diagnosis of $\mathrm{VL}$ is now to improve the reproducibility and field applicability of PCR based methods. The introduction of Leishmania OligoC-Test and NASBAOligochromatography (OC) in dipstick format is a step forward in this direction. Both tests are available as self-containing kits and have shown high sensitivity and specificity in Sudan, Peru and Kenya $[17,18]$.

Another advancement in molecular based detection is Loopmediated isothermal amplification which does not require sophisticated machinery, cold chain for storing reagents and positivity can be judged visually based on the turbidity of reaction mixture and therefore can have wide field applicability if developed further. A recent study from Bangladesh has shown encouraging results with LAMP with a diagnostic sensitivity of $90.7 \%$ and $100 \%$ specificity [19]. The laboratory diagnosis of VL has seen tremendous progress during the last decade and will definitely play an important role in VL elimination program by developing more rapid, sensitive, less expensive and non-invasive diagnostic procedures.

\section{References}

1. Alvar J, Vélez ID, Bern C, Herrero M, Desjeux P, et al. (2012) Leishmaniasis worldwide and global estimates of its incidence. PLoS One 7: e35671.

2. Sundar S, Chakravarty J, Agarwal D, Rai M, Murray HW (2011) Single-dose liposomal amphotericin B for visceral leishmaniasis in India. N Engl J Med 362: 504-512.

3. Sundar S, Rai M (2002) Laboratory diagnosis of visceral leishmaniasis. Clin Diagn Lab Immunol 9: 951-958.

*Corresponding author: Dr. Vijay Kumar Prajapati, Assistant Professor, Department of Biochemistry, School of Life Sciences, Central University of Rajasthan, Bandar Sindri, Ajmer, 305 801, Rajasthan, India, E-mail: vijay84bhu@gmail.com

Received August 20, 2013; Accepted August 22, 2013; Published August 24 2013

Citation: Prajapati VK, Mehrotra S (2013) Advances in the Diagnosis of Viscera Leishmaniasis. J Mol Biomark Diagn 4: e118. doi:10.4172/2155-9929.1000e118

Copyright: (c) 2013 Prajapati VK, et al. This is an open-access article distributed under the terms of the Creative Commons Attribution License, which permits unrestricted use, distribution, and reproduction in any medium, provided the original author and source are credited 
Citation: Prajapati VK, Mehrotra S (2013) Advances in the Diagnosis of Visceral Leishmaniasis. J Mol Biomark Diagn 4: e118. doi:10.4172/21559929.1000 e118

4. Maurya R, Mehrotra S, Prajapati VK, Nylén S, Sacks D, et al. (2011) Evaluation of blood agar microtiter plates for culturing leishmania parasites to titrate parasite burden in spleen and peripheral blood of patients with visceral leishmaniasis. J Clin Microbiol 48: 1932-1934.

5. Sundar S, Singh RK, Maurya R, Kumar B, Chhabra A, et al. (2006) Serological diagnosis of Indian visceral leishmaniasis: direct agglutination test versus rK39 strip test. Trans R Soc Trop Med Hyg 100: 533-537.

6. Vaish M, Bhatia A, Reed SG, Chakravarty J, Sundar S (2012) Evaluation of rK28 antigen for serodiagnosis of visceral Leishmaniasis in India. Clin Microbiol Infect 18: 81-85.

7. Vaish M, Sharma S, Chakravarty J, Sundar S (2012) Evaluation of two nove rapid rKE16 antigen-based tests for diagnosis of visceral leishmaniasis in India. J Clin Microbiol 50: 3091-3092.

8. Chappuis F, Sundar S, Hailu A, Ghalib H, Rijal S, et al. (2007) Viscera leishmaniasis: what are the needs for diagnosis, treatment and control? Nat Rev Microbiol 5: 873-882.

9. Vaish M Singh OP, Chakravarty J, Sundar S (2011) rK39 antigen for the diagnosis of visceral leishmaniasis by using human saliva. Am J Trop Med Hyg 86: 598-600

10. Khan MG, Alam MS, Podder MP, Itoh M, Jamil KM, et al. (2010) Evaluation of rK-39 strip test using urine for diagnosis of visceral leishmaniasis in an endemic area in Bangladesh. Parasit Vectors 3: 114.

11. De Colmenares M, Portus M, Riera C, Gallego M, Aisa MJ, et al. (1995) Short report: detection of $72-75-k D$ and $123-k D$ fractions of Leishmania antigen in urine of patients with visceral leishmaniasis. Am J Trop Med Hyg 52: 427-428.
12. Srivastava P, Mehrotra S, Tiwary P, Chakravarty J, Sundar S (2012) Diagnosis of Indian visceral leishmaniasis by nucleic acid detection using PCR. PLoS One 6: e19304.

13. Vaish M, Mehrotra S, Chakravarty J, Sundar S (2011) Noninvasive molecular diagnosis of human visceral leishmaniasis. J Clin Microbiol 49: 2003-2005.

14. Cruz I, Millet A, Carrillo E, Chenik M, Salotra P, et al. (2013) An approach for interlaboratory comparison of conventional and real-time PCR assays for diagnosis of human leishmaniasis. Exp Parasitol 134: 281-289.

15. Mary C, Faraut F, Lascombe L, Dumon H (2004) Quantification of Leishmania infantum DNA by a real-time PCR assay with high sensitivity. J Clin Microbio 42: 5249-5255.

16. Basiye FL, Mbuchi M, Magiri C, Kirigi G, Deborggraeve S, et al. (2010) Sensitivity and specificity of the Leishmania OligoC-TesT and NASBAoligochromatography for diagnosis of visceral leishmaniasis in Kenya. Trop Med Int Health 15: 806-810.

17. Saad AA, Ahmed NG, Osman OS, Al-Basheer AA, Hamad A, et al. (2010) Diagnostic accuracy of the Leishmania OligoC-TesT and NASBAOligochromatography for diagnosis of leishmaniasis in Sudan. PLoS Negl Trop Dis 4: e776

18. Espinosa D, Boggild AK, Deborggraeve S, Laurent T, Valencia C, et al. (2009) Leishmania OligoC-TesT as a simple, rapid, and standardized tool for molecula diagnosis of cutaneous leishmaniasis in Peru. J Clin Microbiol 47: 2560-2563.

19. Khan MG, Bhaskar KR, Salam MA, Akther T, Pluschke G, et al. (2012) Diagnostic accuracy of loop-mediated isothermal amplification (LAMP) for detection of Leishmania DNA in buffy coat from visceral leishmaniasis patients. Parasit Vectors 5: 280 